\title{
Single and dual chamber pacemaker implantation in patients with left superior vena cava persistence - own experiences
}

\author{
Anna Żabówka, Jakub Kotarba, Zbigniew Siudak, Dariusz Dudek \\ Department of Interventional Cardiology, Jagiellonian University Medical College, Krakow, Poland
}

Adv Interv Cardiol 2017; 13, 2 (48): 170-172

DOI: https://doi.org/10.5114/pwki.2017.68064

\section{Introduction}

Persistent left superior vena cava (LSVC) is a rare syndrome occurring in ca. $0.3 \%$ of the population without congenital heart defects. Most frequently this syndrome has no symptoms and is discovered incidentally during the autopsy or pacemaker or cardioverter-defibrillator implantation trials [1-3]. Ninety-two percent of cases show that the persistent left superior vena cava passes to the enlarging coronary sinus and subsequently to the right atrium. Left superior vena cava is observed in about $10 \%$ of the population with congenital heart defects, in which $0.07-0.13 \%$ of the LSVC cases are accompanied by atresia of the proper right superior vena cava $[4,5]$. The aforementioned cases show that LSVC is the only blood vessel which pumps out blood from the upper part of the body and may result in severe technical problems as well as the vena cava superior syndrome [1-4, 6-8]. According to the relevant literature, the anomalies described herein are frequently accompanied by arrhythmic disorders, e.g. short PQ, syndrome of malfunctioning sinus node, ectopic atrial rhythms, total atrioventricular block and tachyarrhythmia [7].

Presence of the LSVC is a direct result of improper venous system development in the early stage of embryo evolution. In the first weeks of life the two anterior essential veins conduct part of the cranial blood. Analogically, two posterior essential veins conduct blood from the lower body parts. At the end of the second month of the embryo's life, after enablement of sinus venosus to the right atrium, both anterior essential veins form an anastomosis, which then transforms into the left brachiocephalic vein. Disappearance of the left anterior essential vein below the anastomosis may be observed at a later stage. Furthermore, the section above transforms into the left internal jugular vein. The right anterior essential vein is preserved entirely and its frontal section forms the analogical right internal jugular vein. The section below the right subclavian vein estuary transforms into the right brachiocephalic vein. Similarly, the section below the left brachiocephalic vein transforms into the LSVC [6-10].

\section{Aim}

The aim of this work was to determine the prevalence of LSVC and its impact on the course and the number of complications during PM implantation.

\section{Material and methods}

Four examples of LSVC are described in this article, all detected during elective PM implantation in patients with symptomatic sinus node disease. In all cases a venography examination was performed before the implantation, which revealed LSVC presence. Data for 498 consecutive patients between 06.2010 and 06.2016 have been analysed retrospectively.

\section{Results}

Case 1: A $58 \mathrm{~cm}$ electrode was inserted through the coronary sinus into the right ventricle and implanted at the base of the chamber. Subsequently a $58 \mathrm{~cm}$ atrial electrode was implanted in the right auricle. Six days after PM implantation an ventricular electrode dislocation was observed. It led to reimplantation intervention during which the electrode was replaced with a longer active fixation electrode (Figure $1 \mathrm{~A}$ ).

Case 2: A $58 \mathrm{~cm}$ electrode was inserted through the coronary sinus into the right ventricle and implanted by the outflow of the chamber. Subsequently a $52 \mathrm{~cm}$ auricular electrode was implanted in the right atrium (Figure $1 \mathrm{~B}$ ).

\section{Corresponding author:}

Anna Żabówka, Department of Interventional Cardiology, Jagiellonian University Medical College, 17 Mikołaja Kopernika St, $31-000$ Krakow, Poland, phone: +48 600380 335, e-mail: anna.zabowka@gmail.com

Received: 17.08.2016, accepted: 7.04.2017. 

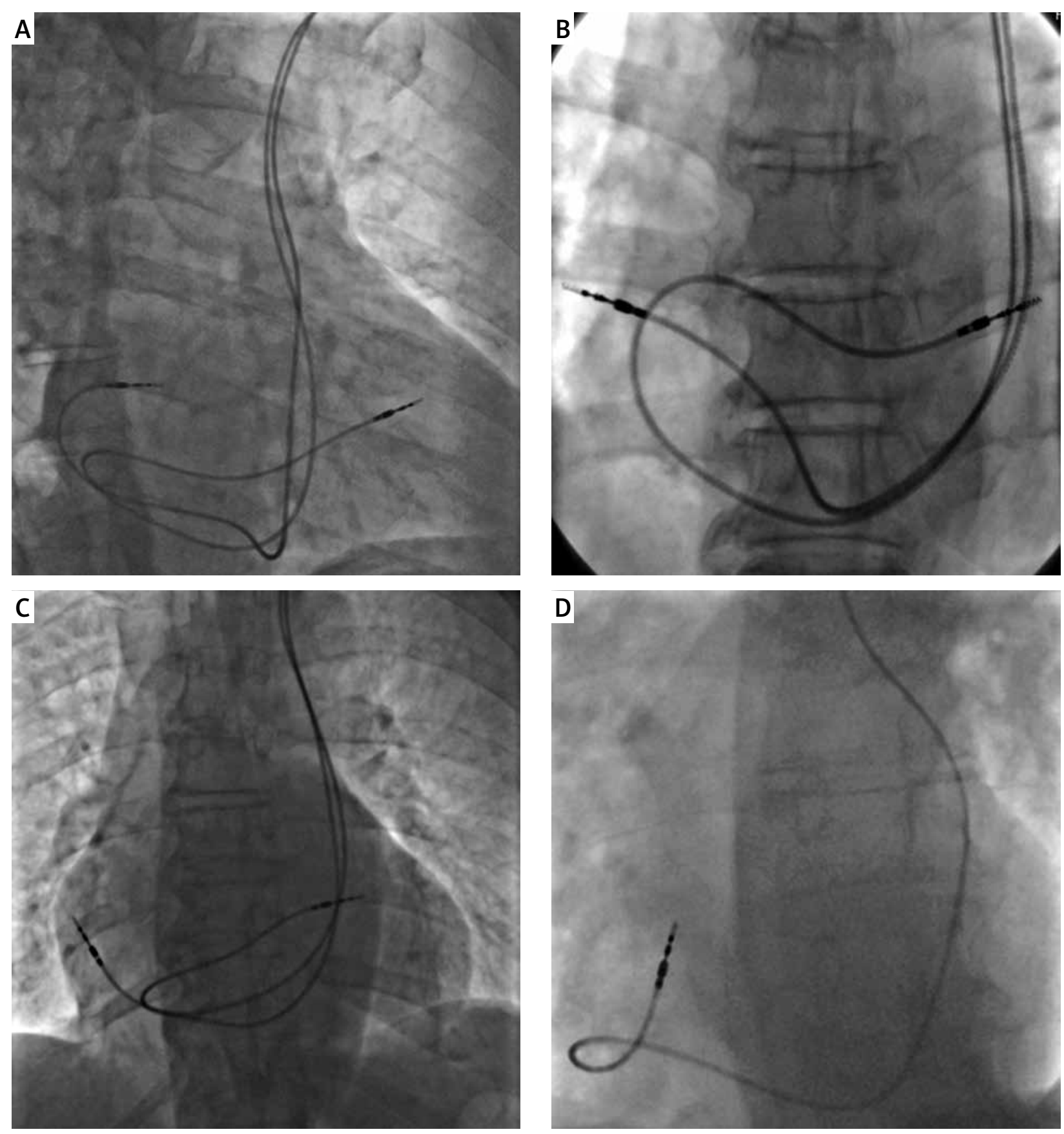

Figure 1. Case examples

Case 3: A $65 \mathrm{~cm}$ electrode was transferred to the right ventricle through the coronary sinus, where the electrode end was placed at $1 / 3$ of the inferior intraventricular septum (IVS). Subsequently a $52 \mathrm{~cm}$ atrial electrode was inserted into the right atrium (Figure $1 \mathrm{C}$ ).

Case 4: A $58 \mathrm{~cm}$ electrode was inserted through the coronary sinus into the right ventricle and implanted at the base of the chamber. Due to persistent atrial fibrillation a VVI-type pacemaker was implanted (Figure $1 \mathrm{D}$ ).

In all cases proper working parameters of the electrodes were achieved with the devices programmed according to current treatment guidelines. The electrodes

were mounted using an active fixation lead in order to mitigate the risk of dislocation. DDDR-type stimulators were used in cases 1-3 and a VVI-type pacemaker in case 4 . All devices were programmed according to current guidelines. Treatment results in all 4 cases were positive. No electrode function disorders or dislocations have been observed in long-term follow-up.

\section{Discussion}

Left superior vena cava presence can be detected by a contrast examination. It usually does not result in major clinical challenges, but may cause technical access issues 
during implantation of the trans-venous pacing system. Nonetheless, in most cases PM/CD implantation through the left subclavian vein is successful. PM/CD implementation through the right subclavian vein or epicardial electrodes may be used in rare cases [1, 4, 5, 9, 11-13]. In addition to the above, the operator might consider alternative solutions such as insertion via the inferior vena cava (IVC) route or application of a new-generation miniaturized trans-catheter pacing system (leadless pacemaker).

The points above are confirmed by Biffi in his 10-year study named "Left Superior Vena Cava Persistence in Patients Undergoing Pacemaker or Cardioverter-Defibrillator Implantation". The study revealed that PM/ICD solution durability does not differ from the overall population in the case of patients with LSVC [1]. Petraca comes to similar conclusions in his twin 10-year study titled "Persistent Left Superior Vena Cava in Patients Undergoing Cardiac Device Implantation: Clinical and Long-Term Data". Petraca states that long-term stimulation system functioning is mainly dependant on coexisting heart diseases, but the sole cardiac device implantation may be disrupted by LSVC presence [14].

Observation results lead to the conclusion that venography is the essential and quickest examination to confirm LSVC, although appliance of the contrasting fluid can result in negative side effects such as nausea, vomiting, skin allergy or gastric allergy including anaphylactic shock. Exclusion or confirmation of coexisting cardiac abnormalities is an important positive side benefit of venography examination. Furthermore, the observation shows that coronary angiography executed before implantation of stimulating devices facilitates the latter. In certain cases it enables the implantation to take place at all. Coronary angiography also results in shortening of the following implantation time and reduces the risk of complications such as emphysema or hematoma caused by an early artery puncture.

Left superior vena cava constitutes a surprise to the operators in most cases; hence proper patient preparation, correct device selection and overall operator's experience were found to be the critical success factors in stimulating device implantation. Observations described herein included 498 implantation cases, out of which 4 were diagnosed as LSVC (a higher frequency than that described in the literature $-0.8 \%$ vs. $0.3 \%$ ). The anomaly did not result in any symptoms perceivable to the patients and each time its discovery was incidental. Left superior vena cava occurrence requires a high level of attention from the operator as it may cause certain difficulties in the implantation process.

\section{Conclusions}

Left superior vena cava presence complicates the procedure and may result in significant extension of time needed for introduction and mounting of electrodes as well as increasing the risk of peri- and post-interventional complications. However, the examples described in this article prove that successful artificial stimulation system insertion without serious complication is possible even if a persistent LSVC has been detected. To conclude - there is no single and definitive procedure that can be recommended if LSVC is detected. The most significant factor of success is the experience of the operator, which might help significantly in finding an alternative solution.

\section{Conflict of interest}

The authors declare no conflict of interest.

\section{References}

1. Biffi M, Boriani G, Frabetti L, et al. Left superior vena cava persistence in patients undergoing pacemaker or cardioverter-defibrillator implantation: a 10-year experience. Chest 2001; 120: 139-44.

2. Schreve-Steensma AM, van der Valk PH, ten Kate JBL, Kofflard MJ. Discovery of a persistent left superior vena cava during pacemaker implantation. Neth Heart J 2008; 16: 272-4.

3. Kilickap M, Altin T, Akyurek O, et al. DDD pacemaker implantation in a patient with persistent left superior vena cava and absent right superior vena cava: a four-year follow-up report. Can J Cardiol 2005; 21: 1221-3.

4. Sankhla V, Vajifdar B, Shah M, Lokhandwala Y. Left sided biventricular pacemaker implantation in the presence of persistent left superior vena cava. Indian Heart J 2010; 62: 344-5.

5. Antonelli D, Rosenfeld T. Implantation of dual chamber pacemaker in a patient with persistent left superior vena cava. Pacing Clin Electrophysiol 1997; 20: 1737-8.

6. Morgan DR, Hanratty CG, Dixon LJ, et al. Anomalies of cardiac venous drainage associated with abnormalities of cardiac conduction system. Europace 2002; 4: 281-7.

7. Beukema RJ, Elvan A, Beukema WP, et al. Cardioverter defibrillator implantation in a patient with absent right superior vena cava. Neth Heart J 2006; 14: 255-7.

8. Kempa M, Lubiński A, Wilczek R, et al. Implantacja kardiowertera-defibrylatora serca u chorego z przetrwałą żyłą główną górną lewą. Kardiol Pol 2006; 4: 1281-3.

9. Hiller S, Zegarska Z. Układ naczyń żylnych. In: Anatomia człowieka. Bochenek A, Reicher M (eds). PZWL, Warsaw 1993.

10. Ostręga M, Tajstra M, Olszowski D, et al. Implantacja kardiowertera-defibrylatora u pacjenta z anomalią rozwojową układu żylnego. Choroby Serca i Naczyń 2013; 10: 159-63.

11. Sarodia BD, Stoller JK. Persistent left superior vena cava: case report and literature review. Respir Care 2000; 45: 411-6.

12. Biffi $M$, Bertini $M$, Ziacchi $M$, et al. Clinical implications of left superior vena cava persistence in candidates for pacemaker or cardioverter-defibrillator implantation. Heart Vessels 2009; 24: 142-6.

13. Arora V, Singh J, Kler TS, et al. Implantable cardioverter defibrylattory implantation in a patient with persistent left superior vena cava and right superior vena cava atresia. Indian Heart J 2005; 57: 717-9.

14. Petraca D, Radeljica V, Pavlovica N, et al. Persistent left superior vena cava in patients undergoing cardiac device implantation: clinical and long-term data. Cardiol Res 2013; 4: 64-7. 